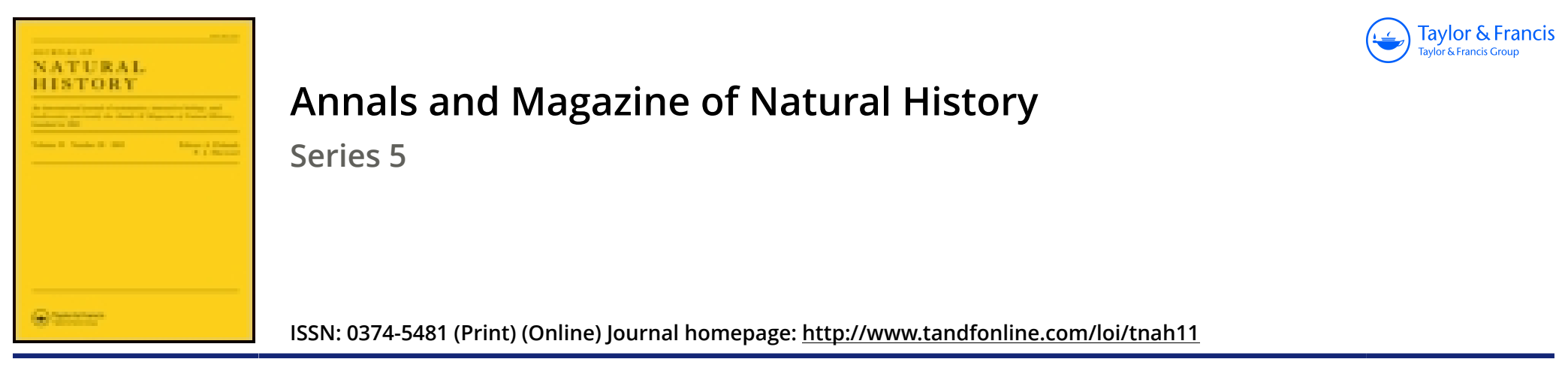

\title{
XXVII.-On the position of the ampullaceous sac and the function of the water canal-system in the Spongida
}

\section{H.J. Carter F.R.S.}

To cite this article: H.J. Carter F.R.S. (1887) XXVII._-On the position of the ampullaceous sac and the function of the water canal-system in the Spongida, Annals and Magazine of Natural History, 19:111, 203-212, DOI: 10.1080/00222938709460228

To link to this article: http://dx.doi.org/10.1080/00222938709460228

曲 Published online: 12 Oct 2009.

Submit your article to this journal $\pi$

Џll Article views: 1

Q View related articles $\sqsubset$ 
XXVII.-On the Position of the Ampullaceous Sac and the Function of the Water Canal-system in the Spongida. By H. J. Carter, F.R.S. \&c.

WHat we want to know in the class of Sponges, after their specific description, is a general conception of the manner in which the different parts of which they are composed are developed, and the way in which their vital functions are performed. In the first instance a useful classification is needed, by which the species may be easily determined: this is the department of the naturalist, and, as a matter of course, precedes all others. The second and third points come under the domain of the physiologist, and here the general plan of development and that of the general way in which the vital forces are maintained (excepting, for a time, their peculiarities) is the primary desideratum. But although the first is a sine quâ non to the latter, it leads to nothing but a collection of curiosities so long as the physiological part remains unknown.

Of course there is much yet to be discovered in the study of a subject so comparatively young as that of spongology, and it is only by numerous contributions arising from a special study of particular parts that this can ever be advanced, and therefore, however restricted the inquiry may be, so long as it tends to elucidate any particular point, the result must be considered acceptable. In the present instance it is the position of the ampullaceous sac in relation to the water-courses or canalicular structure of the sponge to which I wish to direct attention.

The ampullaceous sac ("Geisselkammer" of the Germans) is for the most part spherical in form, consisting of a hollow, thin, transparent sphere of plastic sarcode whose wall is charged with spongozoa ("Geisselzellen" of the Germans), arranged tesserately, that is side by side, or in juxtaposition; the spheroidal form being truncated or cut off, that is absent at one part, whereby a sharply defined circular aperture is produced which opens on a level with the surface of a watercanal, while the other part is imbedded in the substance (plastic connective tissue \&c.) of the sponge immediately underneath. Thus the ampullaceous sac so far resembles the position of a polyp in its fleshy dermal substance; but here the analogy ceases.

I have long since stated (1857) that, when treated with a solution of carmine (that is, of carmine water-colour paint) in the living state, the ampullaceous sacs are the only parts in 
the sponge which take in this colouring-matter, and that, when they are torn to pieces in this state, the carmine paint is found to be in the bodies of the spongozoa.

Further, it was added that it was possible to see the fragments of carmine paint drawn in through the pores on the surface of the sponge, and then, after a break in which they could not be followed, to see them enter the circular opening of the ampullaceous sac, after which they again disappeared for a short interval (probably during the time that the germ or nutritive part of the paint was being abstracted), when fragments of colouring-matter could be seen rushing along: the larger excretory canals, and finally ejected at the single vent, as the particle of growing sponge under observation then consisted of only one "person" (Häckel), and therefore had only one vent.

Thus I never could follow the particles of carmine from the subdermal cavities to the ampullaceous sacs, nor observe the discharged particles coming out of this sac, although my mpression was that they were forced out through the same aperture by which they were taken in.

The ampullaceous sac is not always spherical nor are the spongozoa always grouped into this form, but may vary in number from one to several placed here and there on the surface of the water-cavities or canals, whereby the carmine or indigo paint (for either can be used for this purpose) may be found at isolated points in the sponge-substance apart from the ampullaceous sacs; so that it might be inferred that the ampullaceous sacs are not, as above stated, the only parts which thus take in nutriment; but it should be remembered that it is not the ampullaceous sacs but the spongozoa which do this, and therefore that it is not uncommon to find spongozoa isolated singly or in small groups of different sizes charged with the colouring-matter.

With reference to the passage of the particles of carmine into the sponge through the pores of the surface and the parts into which they may be subsequently received, it might be stated that, so far back as 1869 ('Annals,' vol. iv. p. 191, pl. vii. fig. 5), I described and delineated the fact that in Grayella cyathophora, where the pores on the surface of this siliceous sponge are confined to circumscribed pustuliform areas, the area may open directly into an "excretory canal;" and in 1885 ( $i b$. vol. xv. p. 112, pl. iv. fig. 5) such observations were repeated in Halichondria scabida; while in the interval, viz. in 1879, I pointed out that in Axos spinipoculum the pores of the surface lead directly into an excretory canal through the subdermal cavities. Thus it became 
evident that they were for the purpose of admitting water in to the sponge as well as the nutrient particles which it might contain. Further confirmation of this was adduced by instancing the calcareous sponge Teichonella labyrinthica, wherein the wall is composed, as in the Sycones generally, of hollow cylindrical chambers arranged transversely across it and in juxtaposition, so that the pores are at one end and the vent at the other, viz. on either side of the wall, respectively, while the interior of the chamber is studded all over with spongozoa ('Annals,' 1885, vol. xv. p. 119, pl. iv. fig. 7 \&c.). At this time also I cited two other cases in Psammonematous sponges, viz. in Geelongia vasiformis and Hircinia intertexta, where the pores of the surface opened directly into large excretory canals, that is, of course, through the medium of the subdermal structure. Next, viz. in 1886, I found it most convincingly in a remarkable sponge from "Port Phillip Heads" described under the name of Suberites insignis ('Annals,' vol. xvii. p. 118), wherein the "sinus-like dilatations of the excretory canal-system" are only separated externally from the water by the poriferous epidermis and subjacent subdermal cavities which lie over them at this part. Finally, in 1886, I described and illustrated this in Phloeodictyon birotuliferum, where the digital appendages of this sponge are tubular and hollow, and their wall alone formed of the poriferous and subdermal structures, without, so far as I can see, the trace of an ampullaceous sac, so that the water, with its nutrient particles, must pass directly into the cavity of the process, and the nutrient particles be deflected to their destination afterwards, which probably was in the body of this sponge, of which I only possessed the tubular appendages for description. Moreover, the inner surface of the wall is covered with a layer of epithelial cells like those of the surface.

[It might be here stated that the "skin" of a sponge, so to call it, generally consists of an epidermal or poriferous layer and the subdermal cavities or subdermal structure-the former very thin and composed of a layer of epithelial cells, in which the pores are situated, and the latter comparatively thick and composed of a cancello-clathro-fibro-membranous structure, in which the intervals all communicate with each other; that is, it would be a continuous bollow subdermal cavity but for the presence of this structure. Then comes the body-substance of the sponge, in which the ampullaceous sacs begin to appear. It is the "skin" only which forms the wall of the poriferous tubular processes of Phloodictyon birotuliferum.]

All this shows that the pores are as much for aqueous circulation as for the introduction of nutritive material. 
This having been established, let us now endeavour to trace the nutrient particles from the excretory canals into the ampullaceous sac, and this can be best inferred by finding out the position of the ampullaceous sac and its relation to the excretory canals.

When describing in a general way the structure of a sponge, in the introductory remarks to the order Psammonemata among Mr. Wilson's Australian specimens ('Annals,' 1885, vol. xv. p. 209), it was observed that "what lias been stated of the external parts of the sponge applies cat. par. to the internal ones or parenchyma; for as the sponge grows by the addition of layers to its circumference, that is radiatingly, so the surface of to-day becomes part of the internal structure of to-morrow, and thus somewhat modified it passes into a cancellated form, which is the parenchyma; that is to say, the fibrous skeleton, cored by mineral material or not, becomes a solid mass of reticulation, in which the interstices are tympanized by the still poriferous sarcode (as may be seen in a dried specimen), and the cancellated chambers thus completed. Lastly, the whole is traversed by the branches of the excretory canal-systems. I use the latter in the plural number, because generally every vent indicates a system."

Now here, if I had had the information which I now possess, it might have been added that the "tympanizing sarcode" was charged with ampullaceous sacs and pierced by a number of pores or small holes, which would have so far completed the general description of sponge-structure. But this information has come to me since, partly from a microscopic examination of the tympanizing sarcode in a dry specimen, and partly from that of a small wet one closely allied to Wilsonella australiensis, which will be more particularly described hereafter.

In this small specimen, which hardly exceeds in size an inch each way, the ampullaceous sacs, averaging 20 to 30-6000ths in. in diameter, are unusually well preserved, apparently from natural toughness; but be this as it may, they present themselves under a clear form in which their general outline, as well as that of the spongozon of which they are composed, is sharply defined; moreover they stain well with blue aniline ink, and in comparatively thin slices, that is about 1-24th to 1-16th in. thick, become still more conspicuous under this treatment; so that when the slices are mounted in glycerine and viewed with a magnifying-power of about 90 diameters, in a cell without compression, the ampullaceous sacs can be distinctly seen to surround the water-canals, where they are more or less approximated, apparently unmolested, 
entire, and in situ. Under these circumstances, when a water-canal is selected for observation which has been cut across horizontally so that the eye can be directed into it perpendicularly, one or more ampullaceous sacs may frequently be seen on the confines of the canal in such a position as to show that the greater part of the globular ampullaceous sac is imbedded in the substance of the sponge immediately under the lining membrane of the canal, while the circular aperture opens on a level with it, so that as the water containing the nutritive particles is rapidly carried along them, the latter could be easily deflected from their course and drawn into the ampullaceous sac, while the refuse or unassimilated parts might be discharged through the same aperture, just as takes place in a polyp.

Comparatively thick slices thus treated show the position of the ampullaceous sac more satisfactorily than microscopic thin slices mounted in balsam under compression, especially in the specimen under consideration, wherein their position is rendered additionally clear by not being overcrowded, although both processes have their advantages.

Now I know that in Dr. Huxley's 'Introduction to the Classification of Animals' (1869) a "hypothetical section of Sponyilla" is given (p. 15, fig. 4), wherein the current of water is made to pass in at the pores and through the medium of the subdermal cavity to reach the ampullaceous sac by a canalicular extension of this cavity, after which it makes its exit by a similar opening on the opposite side of the sac into an excretory canal, as if the pores were specially intended for the ampullaceous sacs, that is for the nutritive department. While what I have endeavoured to show is, that the pores are as much for the general circulation or respiratory function as for the introduction of nutriment, and that the ampullaceous sac, being situated on the surface of the excretory canals, only requires a single aperture to fulfil its function.

I am also aware that Dr. F. E. Schulze has always inclined to the view that the ampullaceous sac has two openings, viz. one for bringing in the water and the other for discharging it, as may be seen by one of his latest illustrations ('Der Badeschwamm :' Illustrirte Deutsche Monatshefte, 1882, p. 198, fig. 8), as well as in all those of his previously stained and microtomized preparations of the fleshy and horny sponges published in the 'Zeitschrift f. wiss. Zoologie.' Moreover, in some there is more than one aperture in addition to the large circular or exeretory one represented, amounting in Spongelia avara to "20-30" ("Die Gattung Spongelia," 1878, Zeitschrift f. wiss. Zoologie, Bd. xxxii. p. 134, Taf. viii. fig. 5). 
I cannot say that microscopic slices of stained sponges, reduced to extreme thinness by the microtome and mounted in balsam, that is under compression, are to me so satisfactory as thicker slices simply stained and mounted in glycerine without compression, since in the latter the ampullaceous sacs may be seen in an unmolested state unaltered by any compression or microtomizing, that is entire and in situ. However, there is no objecting to what Schulze has illustrated any further than that it does not seem to me to convey such a general conception of an ampullaceous sac and its position in relation to the water-canal as that which I have seen under the circumstances above mentioned-that is, a globular water-vessel with no neck imbedded in the confines of a water-canal with the mouth opening upon the surface of that canal.

In the syconoid cylindrical chamber of the calcareous sponge Teichonella labyrinthica, which, as I have already stated, is homologous with the ampullaceous sac, there are not only two main openings, that is, pores at one end and a large single vent at the other, but the interior of the chamber is covered with spongozoa intermingled with a great number of other pores or smaller holes ('Annals,' 1885, vol. xv. p. 119, pl. iv. fig. $7 \& \mathrm{c}$.), so that, in fact, it is so far precisely like that which Schulze has described and illustrated in the siliceous sponges. And this structure is continued on to Leuconia nivea and Teichonella prolifera, although the chambers are here so divided up as to resemble both in size and position the ampullaceous sac, which, together with the now tree-like form of the water canal-system opening as vents and pores respectively on the surface (as there is no cloaca in these species), renders the whole almost identical with that of the siliceous sponge.

I have stated that " there is no cloaca" in Leuconia nivea and Teichonella prolifera; but the fact is that the termination of the large canal of the water-systems respectively in all sponges is but a modified cloaca, and therefore those of Leuconia nivea and Teichunella prolifera must be considered the same; but for distinction sake it is necessary to separate them from those Calcispongix which possess that particular kind of ending of the excretory canal-systems which has been distinguished by the name of "cloaca," of which many similar instances exist in the adult forms of the siliceous sponges.

This, however, does not interfere with the fact that the admission of water for respiratory purposes, while it also carries in with it the elements of nutrition, is effected through the pores or inhalant orifices of the surface, while the discharge takes place at the vent or exhalant orifice at the other end of the cylindrical chamber. 
Lastly, in a portion of tympanizing sarcode cut out from a dried fragment of Geelongia vasiformis and placed under a power of about 500 diameters, the ampullaceous sacs in juxtaposition, although $d r y$, may be distinctly seen on the tympanizing sarcode with their circular apertures still open in many instances.

To return, however, to the position of the ampullaceous sac in the specimen of Wilsonella to which I have alluded, there can be no doubt that when brought into view in the interior of the sponge in a thin slice stained and mounted in glycerine, as above mentioned, it may be seen in more or less plurality and more or less approximated on the confines of the smaller excretory canals, where these have been so cut across as to enable the observer to look down into them. Instances then present themselves where the sharply-defined globiform ampullaceous sac may be seen to rest on its side in the substance (plastic connective tissue \&c.) of the sponge immediately under the surface-membrane or epithelium of the canal with its circular mouth opening on a level with the latter.

As above stated also, the shape of the ampullaceous sac is not invariably globiform, but in no instance have I been able to see any other canal in connexion with it than that of the excretory system, on the surface of which the "circular aperture" opens. Nor have I in any instance been able to trace any canals leading directly from the pores on the surface into anything but the cancello-clathrate subdermal structure, within which the ampullaceous sacs, according to my observation, only begin first to appear, that is in the body-substance of the sponge.

Still, it has often appeared to me that the ampullaceous saes, when grouped together in a massive form, are fixed in a kind of fibrous trama wherein they are connected with one another by tubular intercommunication, which may finally open upon the surface of an excretory canal. Nor have I been able to see the circular aperture in any of these instances, where it might have been hidden by the smallness of the excretory canal among the aggregated ampullaceous sacs. In short, I have never been able to see the circular aperture opening upon the surface of the excretory canal, excepting where the ampullaceous sac has been favourably situated for this purpose, as above mentioned.

I do not wish it to be inferred for a moment from what is above stated that I discredit anything that has been published by Dr. F. E. Schulze; indeed, what he has stated with respect to the incurrent and excurrent apertures of the ampullaceous sac is verified in the chamber of Teichonella labyrinthica, 
which is the homologue of the ampullaceous sac in the siliceous sponges, as above shown. But I desire to put forth my own views of the position of the ampullaceous sac and its relation to the water-canals as deduced from the observations above mentioned.

Probably there is more than one aperture in the ampullaceous sacs in many instances, for I do not see how two could be represented in the microtomized sections unless this had been the case. Then, all I can state is, that there is probably an equal number of instances in which there is only one that serves both purposes, viz. for the inception of the nutrient particles and the exit of the refuse or unassimilated material; which could thus be as easily effected as in a polyp. I have already stated that I never could see any other vessel connected with the ampullaceous sac than the excretory canal.

It is very desirable, however, that more widespread observation on this subject should be made, for it appears to me that the species of Wilsonella which, in conclusion, I am about to describe, is an unusually favourable one for such observations. At the same time I must say that all the more important observations in the physiology of the Spongida that I have made have been obtained by studying living specimens directly and experimentally, which seems to me to be too much neglected now for the description and classification of dead species. But this, of course, necessitates a temporary residence near the places where the freshwater and saltwater species respectively grow. I began my stady of the sponges in this way.

\section{Wilsonella echinonematissima, n. sp.}

Specimen small, without any particular form, being about an inch in diameter each way and composed of a mass of keratose, echinated skeletal fibre covered above by prominent conuli projecting from a smooth surface. Consistence firm, resilient. Colour sponge-amber. Surface even between the conuli, which are large, obtuse, distant, and prominent, tied together by the usual fibro-reticulated intervening structure underneath a thin layer of small epithelial cells. Pores grouped together in the epithelial layer over the interstices of the fibro-reticulated structure. Vents not seen. General structure from without inwards consisting of the thin epidermal layer, in which the pores are situated, overlying a comparatively thick one composed of cancello-clathrate fibrous membrane whose intervals intercommunicate with each other throughout, thus corresponding to the "subdermal cavities," resting upon the body-structure of the sponge, which in its 
turn is composed of stiff keratose, profusely echinated fibre, densely reticulated and accompanied by the usual sarcodic or soft sponge-substance, the whole traversed by the branches of the excretory canal-system. Spicules of four forms, viz. :1, skeletal, acuate, smooth, slightly contracted between the obtuse end and the shaft, so as give the former a slightly inflated appearance, about 50 by $1-6000$ th in.; 2, echinating spicules of two sizes, viz. one, the longest, thickly spined about the obtuse or fixed end, scantily over the shaft, and smooth towards the pointed or free end, 35 by $2-6000$ ths in.; the other, the shortest, clavate, much spined about the fixed end, which spination then ceases or is followed by a comparatively smooth interval, and then by another spined portion in which the spines are vertical, after which it is smooth for about a quarter of the length of the spicule, that is to the end of the point, 19 by $2-6000$ ths in. exclusive of the spines, which add another 6000th to the thickness; 3, Hesh-spicule, an equianchorate somewhat bent upon itself, rather obtuse at the ends, $i$. $e$. not navicularly shaped, 6-6000ths in. long by $2 \frac{1}{2}-6000$ ths in. across from the front arm to the back of the shaft. No. 1 forms the core of the keratose fibre, which is profusely echinated with both forms of no. 2 , accompanied by the flesh-spicule no. 3. While the fibre of the body is exclusively that of an Echinonema, that towards the circumference becomes almostas exclusively that of a Psammonematous sponge charged with foreign bodies and terminating in a confused inflated mass at the end of each conulus.

Hab. ? Western Port.

Obs. This is a remarkable sponge, for although the specimen is so small as to be insignificant in size and form, yet it possesses characters which claim for it the title of a distinct species, for which I propose the name above given on account of the density of the echinating part of the spiculation. Here there can be no doubt of the structures of two orders appearing together in the same sponge, for the body-fibre is as essentially that of an Echinonematous as the circumferential or terminal part is that of a Psammonematous sponge, and they are not mixed together as in the fibre of $W$. australiensis. 'The anchorate is less navicular in shape, that is more obtuse at the ends and stouter, than that of Wilsonella australiensis, and the surface, instead of being smooth and overscattered with pustuliform vents, is conulated like that of a Hircinia. There seems, too, to have been a great tendency in its development to the formation of kerasine, for bodies as large as the cells of Polyzoa that have been in its proximity, and even the cells themselves of these animals, have become 
attached to the fibre by an enveloping extension of the profusely echinated layer over them. But the most striking part of all is the sharply-defined and persistent character of the ampullaceous sacs, which, being comparatively scanty and more or less separated, besides possessing an unusual degree of toughness under manipulation, have enabled me to make with certainty the observations above mentioned.

P.S.-In the "Supplement" to the descriptions of Mr. Wilson's sponges, published in the 'Annals' of 1886, vol. xviii. p. 271, for "Port Western" read "Western Port." And for "Histioderma," p. 452 et seq., read "Histoderma."

XXVIII.-Description of a new Genus of Stylasteridæ. By R. Kirkpatrick, Assistant, British Museum (Natural History).

[Plate VIII.]

THE specimen described here was collected off Mauritius, and obtained from Mr. De Robillard. No information was sent concerning the depth at which it was found or the manner in which it was obtained.

\section{Phalangopora, g. n.}

Ramose Stylasteridæ with gastropores in a single linear series on the anterior and posterior surfaces of the branches of the colony; with dactylopores arranged in a single linear series on each lateral surface of each branch, and also irregularly scattered. Mouth of each gastropore overarched by a triangular scale; dactylopores with nariform projections. Both kinds of pores without styles?

\section{Phalangopora regularis, sp. n. (Pl. VIII.)}

Colony tlabelliform; dichotomous branching fairly well indicated in parts; branches subcylindrical, flattened on anterior and posterior surface; parent branch 3 millim. in diameter, terminal branches 1 millim.; surface marked by wavy ridges running in a longitudinal direction; pores small, gastropores measuring $\cdot 5$ millim. from side to side, $\cdot 3$ millim. from before backwards, mouth opening obliquely and overhung by a triangular slightly convex scale with rounded apex; dactylopores oval in projection, slightly constricted in the middle, long diameter $\cdot 3$ millim., transverse $\cdot 15$ millim., height of nariform projections 15 millim. Ampullæ hemispherical, $1 \cdot 2$ millim. iu diameter.

Loc. Mauritius. 